\title{
Awareness and practice of patients' rights among hospitalized patients at Wad-Medani Teaching Hospital, Sudan
}

Abobaker A.H. Younis ${ }^{1}$, Amal H.A. Hassan ${ }^{1}$, Eylaph M.E.H Dmyatti ${ }^{1}$, Mehad A.H. Elmubarak ${ }^{1}$, Rahma A.A. Alterife ${ }^{1}$, Rawan E.O. Salim', Samar A.B. Mohamed ${ }^{1}$ and Wefag S.A.M. Ahmed ${ }^{7}$

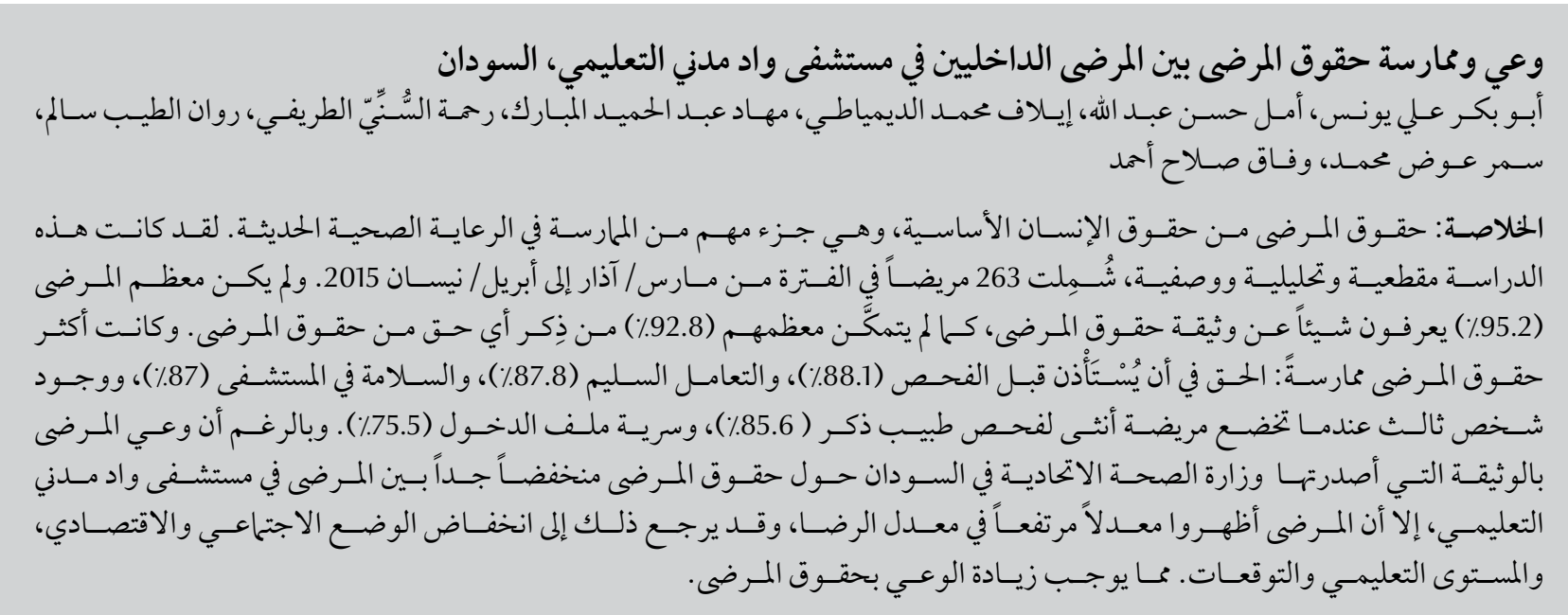

ABSTRACT Patients' rights are a fundamental human right and an important part of modern health care practice. This is a cross-sectional descriptive analytic study, conducted amongst 263 patients at Wadi-Medani Teaching Hospital, Sudan, in March-April 2015. Most patients (95.2\%) did not know about the Bill of Rights and most of them (92.8\%) were not able to mention any of the patients' rights. The most practiced rights were: the right to be asked for permission before examination (88.1\%), proper handling $(87.8 \%)$, safety of the hospital $(87 \%)$, presence of a third person when examining a female by a male doctor (85.6\%), and admission file confidentiality (75.5\%). The awareness of Sudan FMOH Patients' Bill of Rights was very low among patients at Wad-Medani Teaching Hospital, yet they showed a high satisfaction rate probably due to their low socioeconomic status, educational level and expectations. Therefore, awareness of patients' rights must be increased.

\section{Connaissance et pratique des droits des patients parmi les patients hospitalisés de l'hôpital universitaire de} Wad-Medani, au Soudan

RÉSUMÉ Les droits des patients constituent un droit humain fondamental et représentent une partie importante de la pratique des soins de santé modernes. Le présent article concerne une étude analytique descriptive transversale menée auprès de 263 patients entre mars et avril 2015. La plupart des patients (95,2 \%) n'étaient pas au courant de l'existence de la déclaration des droits, et la majorité d'entre eux $(92,8 \%)$ n'était pas en mesure de citer ne seraitce qu'un droit des patients. Les droits appliqués le plus souvent étaient les suivants : le droit à être consulté avant tout examen clinique $(88,1 \%)$, un traitement adéquat $(87,8 \%)$, la sécurité des hôpitaux (87 \%), la présence d'une tierce personne lors de l'examen d'une patiente par un docteur de sexe masculin $(85,6 \%)$, et la confidentialité des dossiers d'admission (75,5\%). Un très faible pourcentage des patients de l'hôpital universitaire de Wad-Medani avait connaissance de la déclaration des droits des patients du ministère fédéral de la Santé soudanais. Pour autant, les patients affichaient un taux élevé de satisfaction, certainement dû à leur faible statut socio-économique, à leur bas niveau d'éducation et à leurs attentes limitées. La connaissance du droit des patients doit donc être améliorée. 


\section{Introduction}

Patients' rights are a fundamental human right, and a quality assurance that measures and protects patients against abuse and discrimination and promotes ethical practices $(1,2)$. Patients' rights are an important part of modern healthcare practice. Perhaps, patients are one of the most vulnerable groups in society. Therefore, improving the rights of patients is considered a priority in the provision of medical services and one of the medical indices in every society (3). The relationship between physicians and their patients has undergone significant changes recently. While a physician should always act according to his/her conscience, and always in the best interests of the patient, equal effort must be made to guarantee patient autonomy and justice. Physicians and other persons or bodies involved in the provision of health care have a joint responsibility to recognize and implement patients' rights (4).

Since the United Nations Declaration of Human Rights in 1948 (1), legislation on patients' rights has been passed worldwide (5). There have been many declarations defining the importance of patients' rights. The American Hospital Association and the World Medical Association adopted declarations of patients' rights in 1973 and 1981, respectively $(4,6)$.

The World Health Organization (WHO) research group on patients' rights and citizens' empowerment has suggested that each country should articulate its concerns and priorities according to its own cultural and social needs to promote and protect patients' rights (7). In response, the Sudan Federal Ministry of Health (FMoH) launched a Patients' Bill of Rights in 2009 (8). This Bill is one of the earliest among Arab countries. The WHO also cautions that "the existence of Patients' Charters without efforts to raise awareness among patients does not improve the quality of health care" (9).
The significance of the present study relies on the fact that patient care is the ultimate goal of medical schools and healthcare institutions. This study offers an opportunity to assess patients' awareness and satisfaction regarding their rights, and could drive the attention of the community towards this issue. Moreover, there is lack of similar studies regarding this subject locally and regionally. This study was conducted to assess the awareness and practice of patients' rights among inpatients at Wad Medani Teaching Hospital, Gezira, Sudan.

\section{Methods}

\section{Study design and setting}

This cross-sectional, descriptive analytical study was conducted between March and April 2015 in Wad-Medani Teaching Hospital, Gezira, Sudan, which is the largest governmental hospital outside the capital Khartoum. The hospital has 254 beds with a mean number of 820 admissions per month and a mean bed turnover of 3.8. The study population was selected from all wards of the hospital: internal medicine, surgery, chest and ear, nose and throat.

\section{Sample selection}

The sample size was based on prevalence of $50 \%$ with $95 \%$ confidence level and 5\% level of significance; the required sample was at least 263 participants. All admitted patients during the study period who agreed to participate and could communicate with us were included. Patients who refused to participate, were critically ill or could not communicate with us were excluded. A cluster sampling technique was used, in which each department was considered as a cluster. The sample size for each department was proportional to its mean number of admissions, as follows: internal medicine, surgery, chest and ear, nose and throat $(147,92,1$ and 23 , respectively). All patients who met the inclusion criteria were randomly selected.

\section{Questionnaire}

The questionnaire comprised two parts. The first part included questions regarding sociodemographic data such as age, sex, marital status, residency, duration of hospitalization and educational status. In the second part the patients' awareness and practice of patients' rights were evaluated using a 5-point scale. The questions were based on the Sudanese FMoH Patients' Bill of Rights (8). It consisted of 28 questions in 5 domains: availability of fundamental services (3 questions); access to services (5 questions); appropriate clinical practice (11 questions); appropriate nursing services (4 questions); and other services (5 questions).

\section{Data collection and analysis}

The authors (class of 2017 medical students) interviewed the patients and recorded their answers. The patients' identities were kept confidential and they were assured that any information given would only be used for scientific research. The response rate was $97.4 \%$ of the recruited patients and only a few refused. Data was analyzed using SPSS version 20. $P<0.05$ was considered to be significant.

\section{Ethical considerations}

The study was approved by the Research Ethical Committee, Faculty of Medicine, University of Gezira and the administration of Wad Medani Teaching Hospital. Verbal consent was obtained from the participants.

\section{Results}

A total of 263 patients were interviewed. Table 1 shows the sociodemographic characteristics of the study sample: $58.17 \%$ were female and $41.8 \%$ male and mean age was 45 years (range: 17-90 years). Regarding residency, 


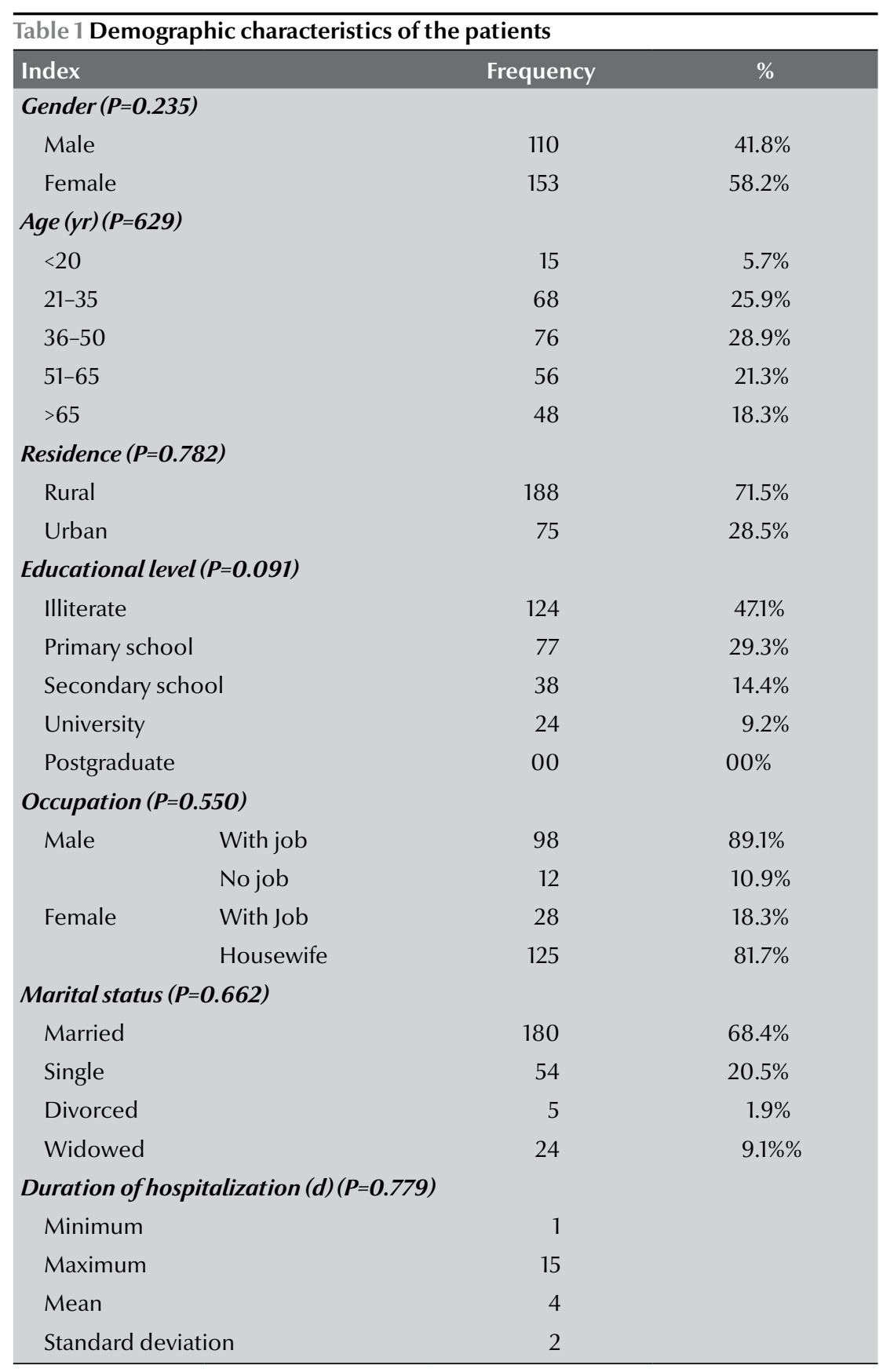

$71.5 \%$ were from rural areas. Most of the participants were married and around one-third of the patients were single, divorced or widowed. With regard to occupation: $89.1 \%$ of men had a job, and among women, $18.3 \%$ had a job and $81.7 \%$ were housewives. With regard to education, $47.1 \%$ were illiterate, while $29.3 \%$ had primary school education and $23.6 \%$ had secondary school education or above. The mean duration

\section{Practice of patients' rights}

The most practiced rights from the patients' perspective were: appropriate handling $(87.8 \%)$, the right to be asked for permission prior to examination $(87.1 \%)$, hospital safety (87\%), presence of a third person when a male doctor examines a woman (85.6\%), and confidentiality of the admission file $(74.9 \%)$. The least practiced rights were: ease of presenting complaints (52.2\%), awareness of hospital scheduled working hours (51.3\%), being informed about medication use and adverse effects (41\%), and involvement in decision making (37.6\%).

\section{Availability of fundamental services}

About half of the patients (51.3\%) totally disagreed/disagreed about awareness of hospital scheduled working hours, while $43.3 \%$ totally agreed/agreed ( $\mathrm{Ta}$ ble 2). Similarly, 50.9\% totally agreed/ agreed upon the presence of a hygienic hospital environment, while 30.8\% totally disagreed/disagreed. Most of the participants (87\%) totally agreed/ agreed about the safety of the hospital and only $11.4 \%$ totally disagreed/disagreed.

\section{Access to services}

When asked about the ease of reaching different hospital departments: $69.9 \%$ of patients totally agreed/ agreed (Table 2). Among these, 10.3\% reach different sections by reading building signs, $77.2 \%$ by asking for directions and $38.5 \%$ had previous knowledge (data not shown). Seventy-three percent of patients totally agreed/agreed about being oriented inside the hospital and only $18.3 \%$ totally disagreed/ disagreed. Most of the patients (65.8\%) were aware of health providers' names and titles and $28.1 \%$ totally disagreed/ disagreed. Concerning the presence of appropriate waiting places in the hospital, $66.5 \%$ of respondents totally agreed/agreed, while only $17.1 \%$ totally disagreed/disagreed. One hundred and 


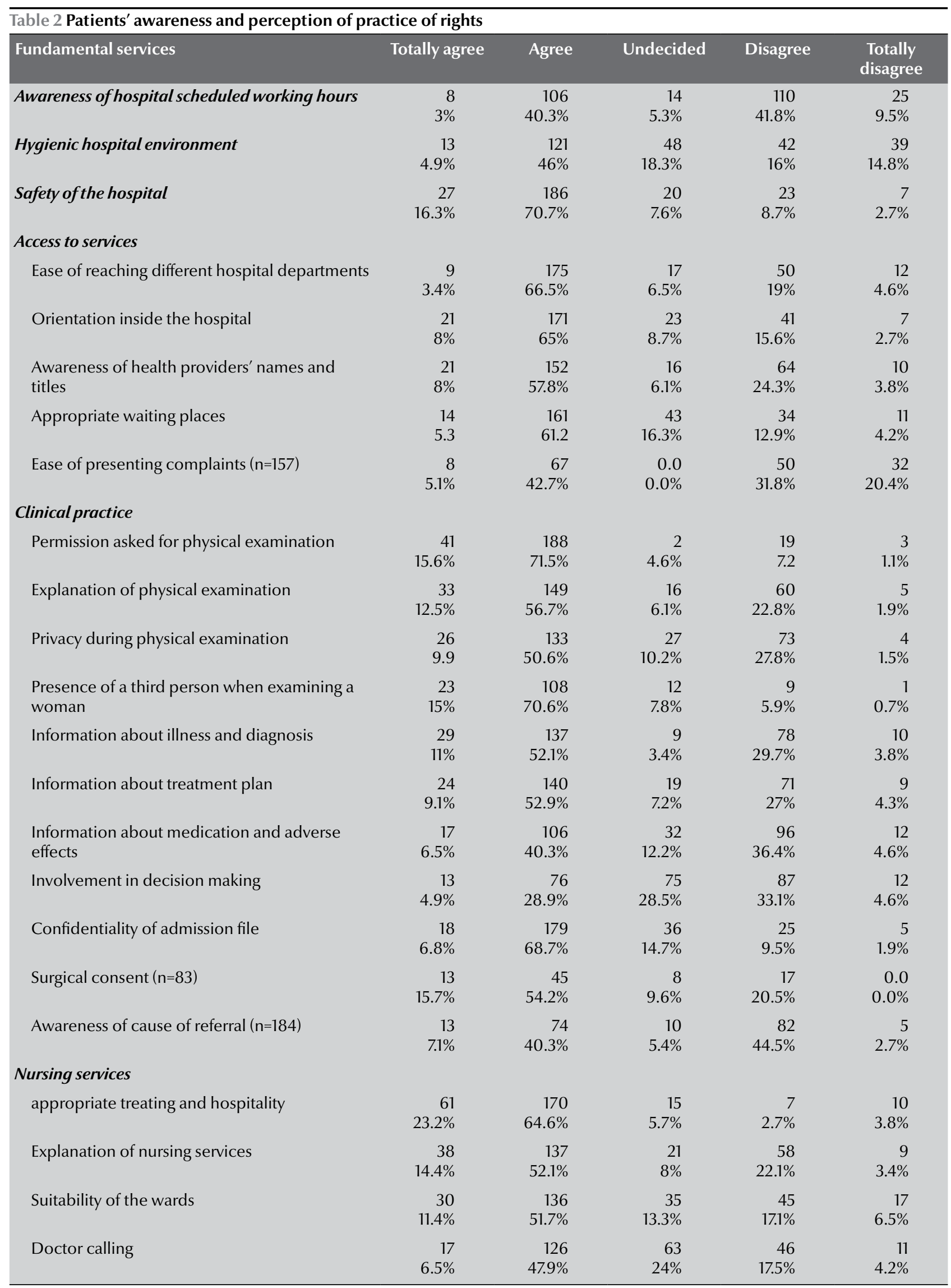


fifty-seven respondents had presented with a complaint previously; around half of them (52.2\%) totally disagreed/ disagreed about ease of presenting complaints, while $47.8 \%$ of them totally agreed/agreed.

\section{Clinical practice}

The majority of participants (87.1\%) totally agreed/agreed about being asked for permission prior to physical examination and $8.3 \%$ totally disagreed/disagreed (Table 2). Most patients (69.2\%) totally agreed/agreed that the doctor explained to them the nature of the physical examination and $24.7 \%$ totally disagreed/disagreed. Over half of the patients $(60.5 \%)$ totally agreed/agreed about being examined in privacy, while $29.3 \%$ totally disagreed/disagreed. Concerning the presence of a third person when a male doctor examined a female patient, $85.6 \%$ totally agreed/agreed, while only $6.6 \%$ totally disagreed/disagreed. Regarding receiving adequate information about their illness and diagnosis, $63.1 \%$ of patients totally agreed/ agreed, while $33.5 \%$ totally disagreed/ disagreed. Almost two-thirds (62.\%) of the respondents totally agreed/agreed about receiving adequate information about their treatment plan, while $31.3 \%$ totally disagreed/disagreed. Just under half $(46.8 \%)$ of the respondents totally agreed/agreed about receiving adequate information about medication use and adverse effects, and $41 \%$ totally disagreed/disagreed. Just over one-third $(37.7 \%)$ of patients totally disagreed/disagreed about being involved in decision making, and a similar number (33.8\%) totally agreed/agreed. Eighty-three $(31.55 \%)$ patients underwent a surgical operation at the hospital. With regard to obtaining surgical consent by the treating doctor: $69.9 \%$ totally agreed/agreed and $20.5 \%$ totally disagreed/disagreed. Almost threequarters of the patients (75.5\%) totally agreed/agreed about the confidentiality of patients' admission files, while only $11.4 \%$ totally disagreed/disagreed.
One hundred and eighty-four (70\%) patients had been referred before. Of those, $47.4 \%$ totally agreed/agreed that they were aware of the cause of their referral, and the same number totally disagreed/disagreed.

\section{Nursing service}

Concerning appropriate treatment and hospitality, $87.8 \%$ of patients totally agreed/agreed and $6.5 \%$ totally disagreed/disagreed. When asked about suitability of the wards $63.1 \%$ of respondents totally agreed/agreed, while $23.6 \%$ totally disagreed/disagreed. For doctor response to patients' request, $54.4 \%$ of participants totally agreed/ agreed, while $21.7 \%$ totally disagreed/ disagreed.

\section{Other services}

Only 9 (3.4\%) patients had met the hospital social workers before. Those patients were asked whether the social worker had provided them with adequate information about the available and suitable type of help. Only 5 (55\%) patients agreed (data not shown). All patients disagreed about the presence of a hospital therapeutic nutrition service and none of them had met a clinical dietician (data not shown).

\section{Practice of patients' rights}

The most practiced rights in patients perspective were: proper handling $87.8 \%$, the right to be asked for permission prior to examination $87.1 \%$, safety of the hospital $87 \%$, presence of a third person when examining a female by a male doctor $(85.6 \%)$ and confidentiality of the admission file $74.9 \%$. The least practiced rights in patients' perspective were: easiness of presenting complaints $52.2 \%$, awareness of working time $51.3 \%$, being informed about medication's use and side effects $41 \%$ and Involvement in decision making $37.6 \%$.

\section{Discussion}

In this cross-sectional descriptive study we were able to assess the awareness and practice of patients' rights among hospitalized patients. We found that awareness about patients' rights was low, and $95.4 \%$ of patients did not know that the Sudanese FMoH had published a Patients' Bill of Rights. These findings could be explained by the lack of distribution of the Sudanese Patients' Bill of Rights.

This is consistent with many studies conducted in the region. Kagoya et al. reported that most patients (81.5\%) had never heard of the Uganda Patients' Charter (10). In a study in Tehran, Davati et al. found that most patients (63.4\%) had not seen the bill of rights (3). In a similar study in Egypt, Zeina et al. reported that most patients (75\%) did not know about the list of patients' rights (11).

In contrast, a study conducted in Malaysia by Yusuf et al. reported that nearly all patients (90\%) were aware of their rights. This could be explained by the revolution in information technology and the higher educational levels of the patient population, and patients and their family members are much better informed about medical matters and they want the best treatment. Another contributing factor is the rise in the standard of living, which has increased consumer awareness and action, accompanied by expectations for higher standards of service (12).

Although patients' awareness was low in our study, there was no significant relationship between sex, age, residency, education and length of stay in hospital and the patients' awareness. However, a study conducted in the Islamic Republic of Iran showed a significant relationship between patients' educational level, residency and their awareness (13).

Our study revealed that the most practiced rights according to the patients' perspective were permission 
prior to examination, appropriate handling, confidentiality of patients' admission files, and safety and cleanliness of the hospital. In contrast, the least practiced rights were awareness about hospital scheduled working hours, receiving information about treatment adverse effects, presenting complains, awareness about cause of referral, and participation in decision making.

In a study conducted by Kagoya et al. in Mulago Hospital in Uganda (10), the most practiced rights were the right to confidentiality and privacy, medical care, and healthy and safe environment; in contrast, the least practiced rights were participation in decision making, participation or representation in development of health policies, and treatment by a named health worker. The study shows that although the Uganda Patients' Charter (14) entitles patients to high-quality services in public hospitals, unethical conduct such as charging illegal fees, discrimination, absconding from duty, negligence, rudeness to patients and physical and emotional abuse deter timely access to and practicing of patients' rights $(2,15)$. Krzych and Ratajczyk in Poland reported that $>80 \%$ of their patients were aware of their right to: choose a treating physician, refuse the proposed treatment, choose the location of treatment, access to medical records, free meals, pastoral care, provide third parties information about health status, and give information to particular persons by telephone (16).
The present study was conducted in a general governmental hospital in Central Sudan. Hence, it reflects the situation in most of the hospitals in the country. The study might not totally reflect the situation in crowded outpatient clinics or that in private hospitals. Another limitation is the lack of similar local studies. There are some difficulties in making comparisons among foreign studies due to different legislation and values, which lead to different perceptions of patients' rights and their observance.

\section{Conclusion}

Awareness of the Sudanese FMOH Patients' Bill of Rights was low among patients at Wad-Madani Teaching Hospital. Patients were satisfied about hospital environment, safety, cleanliness and access to services. They totally agreed that the most practiced rights included being asked for permission before examination, handling in a professional and humane manner, and keeping admission files confidential.

We make the following recommendations.

- Awareness about patients' rights must be increased by widespread distribution of the Sudanese Patients' Bill of Rights among the general public. The FMOH should make more efforts to raise awareness through literacy and linguistic approaches that include audiovisual messages and public bodies, as well as posters in hospitals.

- Awareness of patients' rights among health professionals should be assessed, as they are responsible for implementing such rights. The FMOH should also introduce education about legal aspects of patients' issues through continuous professional development programmes.

- Quality control centres should establish a patients' affairs department in each hospital so that patients are able to demand their rights and present complaints and suggestions.

- The FMOH should commit more funds to ensure availability of basic resources for implementing patients' rights issues, and improving supervision of health workers.

\section{Acknowledgements}

This research was supervised by Dr. Wail N. Mukhtar, Director of the Education Development and Research Center, University of Gezira and Prof. Ahmed A. Mohamadani and Prof. Osman A. Elmustafa for their review and comments. The authors would like to thank the administration of Wad Medani Teaching Hospital for allowing them to interview the patients.

Funding: None.

Competing interests: None declared.

\section{References}

1. United Nations. Universal Declaration of Human Rights; 1948 (http://www.un.org/en/documents/udhr/index.shtml, accessed 16 February 2017).

2. World Health Organization. Basic documents, 45th edition, Supplement, October 2006. Constitution of the World Health Organization. (http://www.who.int/governance/eb/who_ constitution_en.pdf, accessed 13 March 2017).

3. Davati A, Seidmortaz SS, Zafarghandi N, Azimi A, Arbab Solimani S. An assessment of Tehran graduated general physicians' knowledge about the charter of patients' rights. Int Res J. 2012 Apr;3(4):357-61 (http://www.interesjournals.org/ full-articles/an-assessment-of-tehran-graduated-general- physicians-knowledge-about-the-charter-of-patients-rights. pdf?view=inline).

4. World Medical Association. Declaration of Lisbon on the Rights of the Patient (http://www.wma.net/ en/30publications/10policies/14/, accessed 17 February 2017)..

5. World Health Organization. Mental health, human rights and legislation. WHO's framework (http://www.who.int/mental_health/policy/fact_sheet_mnh_hr_leg_2105.pdf, accessed 17 February 2017).

6. Management advisory. A patient's bill of rights. Chicago: American Hospital Association; 1992 (http://www.injured- 
worker.org/Library/Patient_Bill_of_Rights.htm, accessed 13 March 2017)

7. Patients' rights and citizens' empowerment: through visions, to reality: joint consultation between the WHO Regional Office for Europe, Nordic Council of Ministers and The Nordic School of Public Health, Copenhagen, Denmark 22-23 April; Copenhagen: WHO Regional Office for Europe; 2000 (http:// apps.who.int/iris/handle/10665/108313, accessed 17 February 2017).

8. Republic of Sudan, Federal Ministry of Health, Department of Quality Assurance. Sudanese Patients' Bill of Rights. (http:// www.fmoh.gov.sd/quality/Docms/patientRights.pdf, accessed 13 March 2017).

9. World Health Organization. Patient's rights. (http://www.who. int/genomics/public/patientrights/en/, accessed 17 February 2017).

10. Kagoya HR, Kibuule D, Mitonga-Kabwebwe H, Ekirapa-Kiracho E, Ssempebwa JC. Awareness of, responsiveness to and practice of patients' rights at Uganda's national referral hospital. Afr J Prim Health Care Fam Med. 2013;5(1) (http://dx.doi. org/10.4102/phcfm.v5i1.491).

11. Abou Zeina HA, El Nouman AA, Zayed MA, Hifnawy T, El Shabrawy EM, El Tahlawy E. Patients' rights: a hospital survey in
South Egypt. J Empir Res Hum Res Ethics. 2013 Jul;8(3):46-52. PMID:23933775

12. Yousuf RM, Fauzi ARM, How SH, Akter SFU, Shah A. Hospitalised patients' awareness of their rights: a cross-sectional survey from a tertiary care hospital on the east coast of Peninsular Malaysia. Singapore Med J. 2009 may;50(5):494-9. PMID:19495519

13. Mastaneh Z, Mouseli L. Patients' awareness of their rights: insight from a developing country. Int J Health Policy Manag. 2013 Aug;1(2):143-6. PMCID:PMC3937911

14. Republic of Uganda, Ministry of Health, Department of Quality Assurance. Uganda Patients' Charter, October 2009. Kampala: Ministry of Health; 2009 (http://cphl.go.ug/sites/default/ files/library-resources/PATIENTS'\%20CHARTER.pdf, accessed 17 February 2017).

15. Community of Practitioners on Accountability and Social Action in Health. Action Group for Health, Human Rights and HIV/AIDS (AGHA) Uganda. (http://www.copasah.net/ action-group-for-health-human-rights-and-hivaids-agha.html, accessed 13 March 2017).

16. Krzych KJ, Ratajczyk D. Awareness of the patients' rights by subjects on admission to a tertiary university hospital in Poland. J Forensic Leg Med. 2013 Oct;20(7):902-5. PMID:24112342 